\title{
Concurrent occurrence of Sweet's syndrome and erythema nodosum: an overlap in the spectrum of reactive dermatoses
}

\author{
Sanjeev Wasson • Darcy Folzenlogen • \\ Gurushanker Govindarajan
}

Published online: 17 February 2007

(C) Clinical Rheumatology 2007

\section{Clin Rheumatol (2006) 25:268-272}

The name of one of the authors, Gurushanker Govindarajan, was omitted.

The authors would like to retract the Fig. 4 published in the above paper and replace it with the correct figure (below). The published illustration was mistakenly submitted with the article and subsequently published. The authors offer their deepest apologies to Drs. Luis and Celia Requena, whose illustration was first published in Erythema Nodosum, Dermatology Online Journal (2002) 8(1):4.

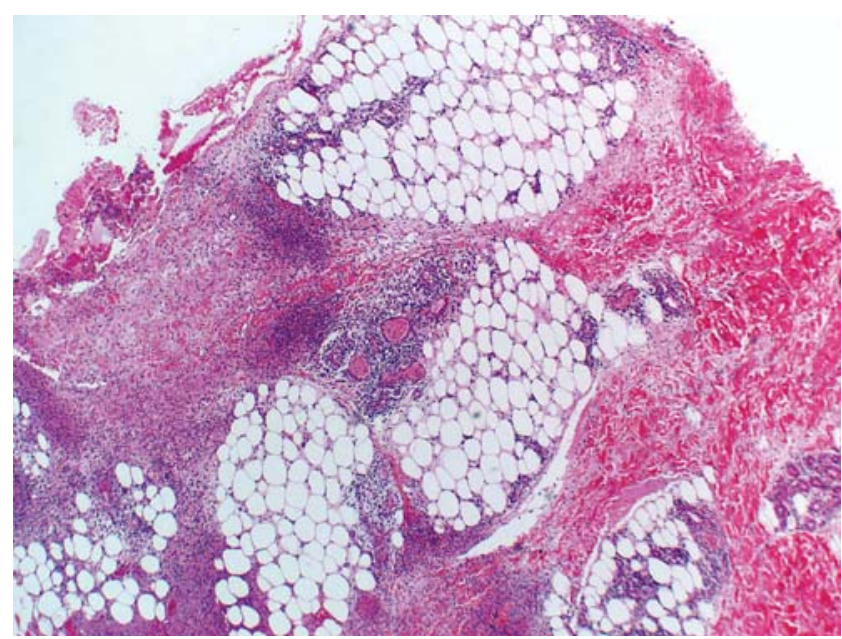

Fig. 4 Erythema nodosum lesion with septal panniculitis in a deeper plane of inflammation. Courtesy of Dr. Yurong Wheeler, MD, Ph.D., and the University of Missouri Healthcare Pathology Department

The online version of the original article can be found at http://dx.doi. org/10.1007/s10067-005-1118-5

S. Wasson $(\bowtie) \cdot$ D. Folzenlogen $\cdot$ G. Govindarajan

Division of Cardiology, Department of Internal Medicine,

University of Missouri-Columbia,

MC 314, McHanney Hall, One Hospital Drive,

Columbia, MO 65212, USA

e-mail: wassons@health.missouri.edu 